\title{
Effect of Human and Bovine Serum Albumin on kinetic Chemiluminescence of Mn (III)-Tetrakis (4-Sulfonatophenyl) Porphyrin-Luminol-Hydrogen Peroxide System
}

\author{
Sayed Yahya Kazemi and Seyed Mohammad Abedirad \\ Department of Basic Sciences, Sari Agricultural Sciences and Natural Resources University, P.O. Box 578, Sari 4818168984, Iran \\ Correspondence should be addressed to Seyed Mohammad Abedirad, mabedirad@yahoo.com
}

Received 25 October 2011; Accepted 22 December 2011

Academic Editor: Xavier Santarelli

Copyright (C) 2012 S. Y. Kazemi and S. M. Abedirad. This is an open access article distributed under the Creative Commons Attribution License, which permits unrestricted use, distribution, and reproduction in any medium, provided the original work is properly cited.

The present work deals with an attempt to study the effect of human and bovine serum albumin on kinetic parameters of chemiluminescence of luminol-hydrogen peroxide system catalyzed by manganese tetrasulfonatophenyl porphyrin (MnTSPP). The investigated parameters involved pseudo-first-order rise and fall rate constant for the chemiluminescence burst, maximum level intensity, time to reach maximum intensity, total light yield, and values of the intensity at maximum CL which were evaluated by nonlinear least square program KINFIT. Because of interaction of metalloporphyrin with proteins, the CL parameters are drastically affected. The systems resulted in Stern-Volmer plots with $k_{Q}$ values of $3.17 \times 10^{5}$ and $3.7 \times 10^{5} \mathrm{M}^{-1}$ in the quencher concentration range of $1.5 \times 10^{-6}$ to $1.5 \times 10^{-5} \mathrm{M}$ for human serum albumin (HSA) and bovine serum albumin (BSA), respectively.

\section{Introduction}

Serum albumins are the most extensively studied and applied proteins because of their availability, low cost, stability, and unusual ligand binding properties. Albumin is the most abundant protein in blood plasma and serves as a depot protein and transport protein for numerous endogenous and exogenous compounds. Albumin is also the main factor in contributing to the colloid osmotic pressure of the blood and has been suggested as a possible source of amino acids for various tissues. Indubitably, albumin is the most multifunctional transport protein and plays an important role in the transport and deposition of a variety of endogenous and exogenous substances in blood [15]. Numerous surveys were focused on determination and study of albumins by spectroscopy, isothermal calorimetery, electrochemistry, fluorescence, light scattering spectroscopy, mass spectroscopy, and chemiluminescence [6-12].

Chemiluminescence (CL) emission is generated by photochemical reactions and results from light being emitted in an exothermic chemical reaction. The attractiveness of chemiluminescence as an analytical tool lies primarily in the simplicity of detection since most samples have no unwanted background luminescence, and no optical filters are required to separate the excitation wavelengths and scatter. Since CL is directly related to the concentration of the reactants, every reaction components, including CL substrate, oxidant, catalyst, cofactor, sensitizer, enhancer, and inhibitor, can affect intensity or decay rate and be determined with low detection limit and wide linear range. More importantly, chemiluminescence is a useful analytical tool for the detection and quantification of a wide variety of biological materials such as cells, microorganisms, proteins, DNA, and RNA too [13-19]. For these reasons, significant interest has existed for application of CL techniques to the analysis of inorganic and organic substances.

The oxidation of luminol (3-aminophthalhydrazide) in alkaline medium is one of the most efficient CL reactions. The produced CL emission is strongly enhanced when some enzymes (e.g., horseradish peroxidase and microperoxidase) or metals (e.g., Co (II), Cu (II), Fe (II), Fe (III), and Mn (III)) are used as a catalyst. It led to produce the excited 3 -aminophthalate anion, which emits light when it is relaxed to the ground state using several oxidants such as permanganate, 


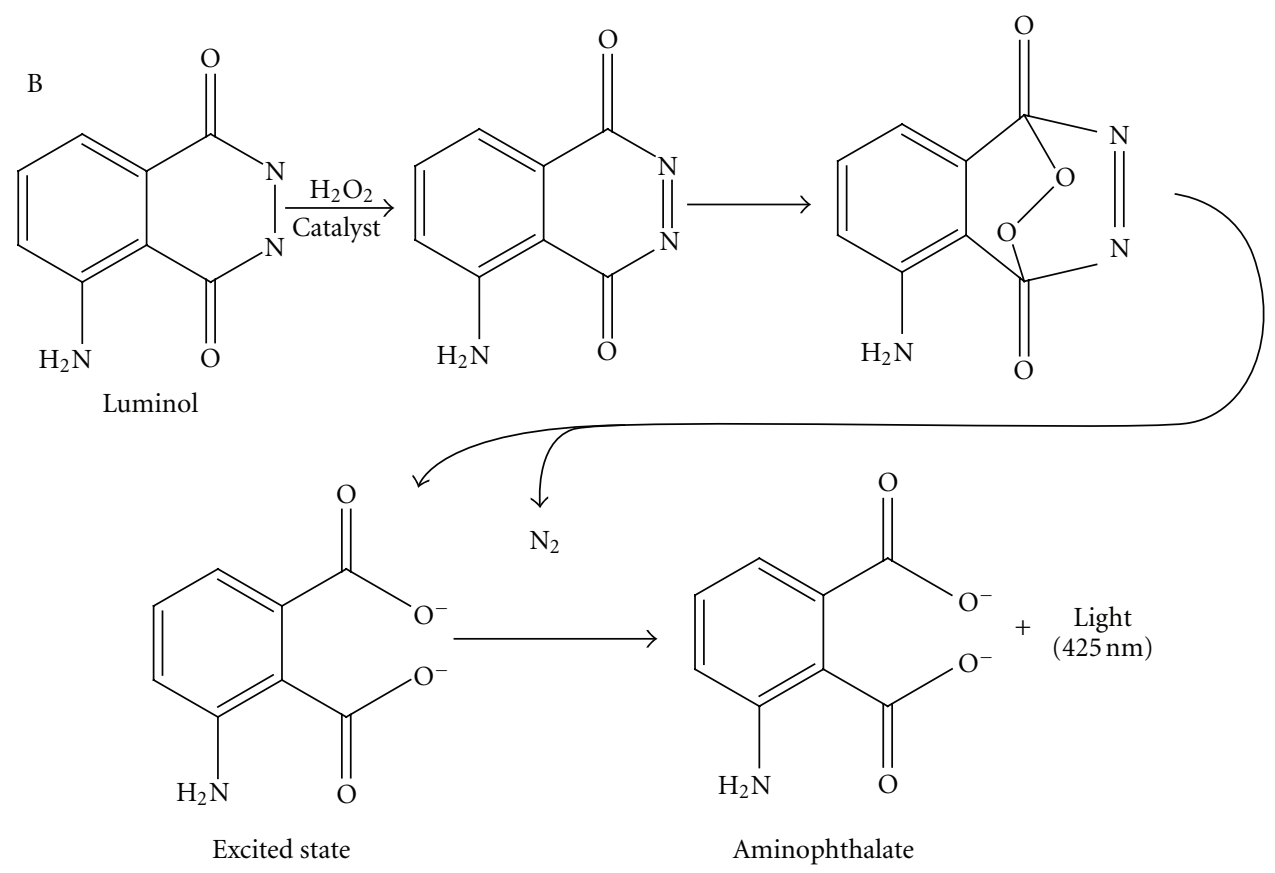

Scheme 1: The mechanism of the CL reaction between luminol and hydrogen peroxide in the presence of catalyst.

periodate, hexacyanoferrate (III), and especially hydrogen peroxide $[13,20]$. The mechanism of the oxidation and lightproducing reaction of luminol is depicted in Scheme 1.

In recent years, mimetic peroxidase supramolecules such as porphyrin, phthalocyanine, and their metal containing analogues have been used as catalyst in CL reaction of luminol. They have many advantages: for example, they are moderately inexpensive and have higher stability at different $\mathrm{pH}$ in comparison with enzymes [21-23]. In this work, manganese tetrasulfonatophenyl porphyrin (MnTSPP) as a good catalyst was employed [21] (the structure is shown in Figure 1).

A continuous interest has been focused on the use of chemiluminescence reactions for the study and detection of proteins [24-32], but as far as we know, few reports have been published to study the influence of proteins on CL kinetic. So, we are interested in investigating the effect of human and bovine serum albumin on kinetic parameters of chemiluminescence reaction of luminol- $\mathrm{H}_{2} \mathrm{O}_{2}$ system in the presence of manganese tetrasulfonatophenyl porphyrin as a catalyst. The investigated parameters include pseudo-firstorder rise and fall rate constant for the chemiluminescence burst, maximum level intensity, time to reach maximum intensity, total light yield, and the values of the intensity at maximum CL.

\section{Materials and Methods}

2.1. Apparatus. Steady-state chemiluminescence measurements were carried out using spectrofluorimeter Shimadzu RF5301PC with the excitation light source being turned off. Intensity as a function of time studies was made on a luminometer equipped with photocell Hamamatsu RX80004 which connected to a personal computer with an appropriate interface. Kinetic parameters were evaluated using KINFIT program. A Metrohm ion analyzer $\mathrm{pH} / \mathrm{mV}$ meter was applied to determine $\mathrm{pH}$.

2.2. Reagents and Solutions. Hydrogen peroxide $(30 \% \mathrm{~V} / \mathrm{V})$, manganese tetrasulfonatophenyl porphyrin (MnTSPP), and sodium hydroxide were purchased from Fluka (Switzerland). Luminol (3-aminophtalhydrazide), human serum albumin (HSA), and bovine serum albumin (BSA) were obtained from Sigma (St. Louis, MO, USA) and used without further purification. Deionized doubly distilled water was used throughout the work.

The stock solution of luminol $(0.05 \mathrm{M})$ was prepared by dissolving $88.5 \mathrm{mg}$ solid in $50 \mathrm{~mL}$ diluted sodium hydroxide solution. $\mathrm{H}_{2} \mathrm{O}_{2}(0.1 \mathrm{M})$ was prepared in water by dissolving $0.5 \mathrm{~mL}$ in a volume of $50 \mathrm{~mL}$. The concentration of $\mathrm{H}_{2} \mathrm{O}_{2}$ was determined by measuring the UV absorbance at $240 \mathrm{~nm}$ using $\varepsilon 240=39.4 \mathrm{~cm}^{-1} \mathrm{M}^{-1}$. The MnTSPP solution was prepared by dissolving in water to the final volume of $25 \mathrm{~mL}$. Stock solutions of proteins were prepared by dissolving the protein in water and stored in a refrigerator at $0-4^{\circ} \mathrm{C}$. The $\mathrm{pH}$ of solution was adjusted by borax- $\mathrm{NaOH}$ buffer $(0.01 \mathrm{M})$.

2.3. Procedure for the Study of CL System. The procedure was carried out in the following manner. The corvette was filled with $1 \mathrm{~mL}$ buffer, $280 \mu \mathrm{L}$ luminol, $150 \mu \mathrm{L}$ serum albumin, and $200 \mu \mathrm{L}$ porphyrin. The samples were placed in luminometer and continuously stirred up with magnetic stirrer (350 rpm). Ten seconds after luminometer began to record, the chemiluminescence reaction was initiated by injecting $250 \mu \mathrm{L}$ hydrogen peroxide to the corvette using a sampler. 


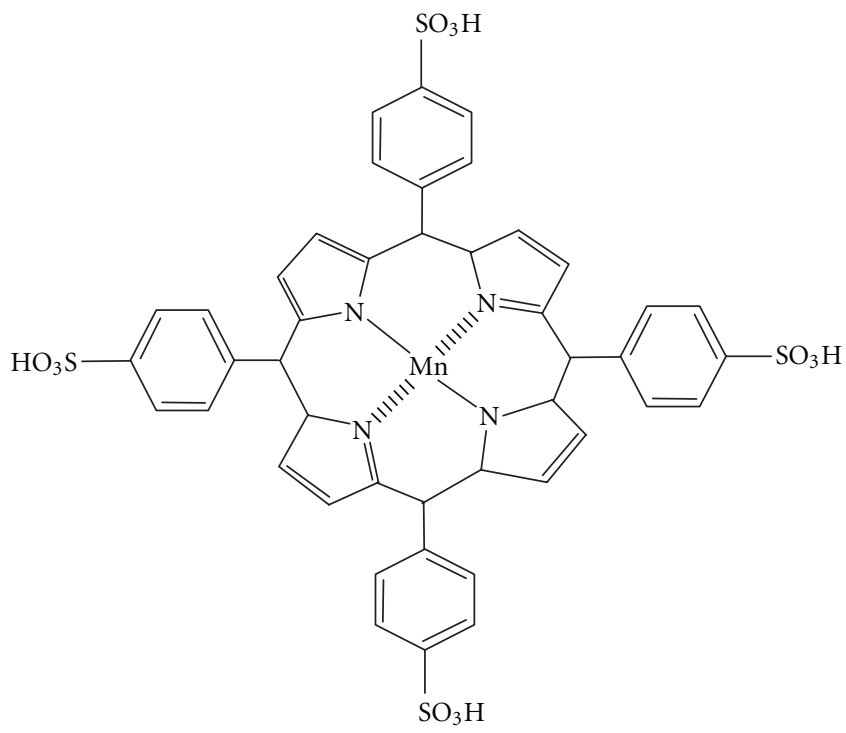

Figure 1: Molecular structure of MnTSPP.

\section{Results and Discussion}

3.1. Optimization of the Factors Affecting CL Intensity. In order to gain more concrete information to optimize CL reaction condition, an investigation was undertaken about the effect of the variables which may affect CL intensity as $\mathrm{pH}$, concentration of luminol, hydrogen peroxide, and manganese porphyrin.

3.1.1. Effect of Luminol Concentration on CL Intensity. Dependence of CL intensity on luminol concentration was studied at the range of $3 \times 10^{-5}$ to $3 \times 10^{-3} \mathrm{M}$ (Figure 2 ). Since maximum intensity was observed at $1 \times 10^{-3} \mathrm{M}$ of luminol, it was chosen as optimal value to obtain highest CL intensity.

3.1.2. Effect of Concentration of $M n$ (TSPP) on Intensity. To investigate the effect of catalyst on chemiluminescence, manganese porphyrin concentration varied from $8 \times 10^{-6}$ to $8 \times 10^{-4} \mathrm{M}$. It was found that the increase of porphyrin concentration up to $2 \times 10^{-4} \mathrm{M}$ leads to the increase in $\mathrm{CL}$ intensity, while at larger concentration, a considerable decrease in intensity was observed. Figure 3 shows variation of intensity as a function of MnTSPP concentration.

3.1.3. Effect of Oxidant on CL Intensity. From the other point of view, to find optimal condition system, hydrogen peroxide concentration ranged from $2 \times 10^{-4}$ to $1.5 \times 10^{-2} \mathrm{M}$ was investigated. It is clear from Figure 4 that a maximum $\mathrm{CL}$ was obtained at $8 \times 10^{-3} \mathrm{M}$, while at higher or lower concentration of hydrogen peroxide, the intensity decreased.

3.1.4. Influence of $p H$ in Study of Proteins by CL. To optimize the effect of $\mathrm{pH}$ of solution on $\mathrm{CL}$, variation of $\mathrm{pH}$ which ranged from 7.5 to 12.5 was studied. It is pertinent to mention that although the maximum catalytic activity

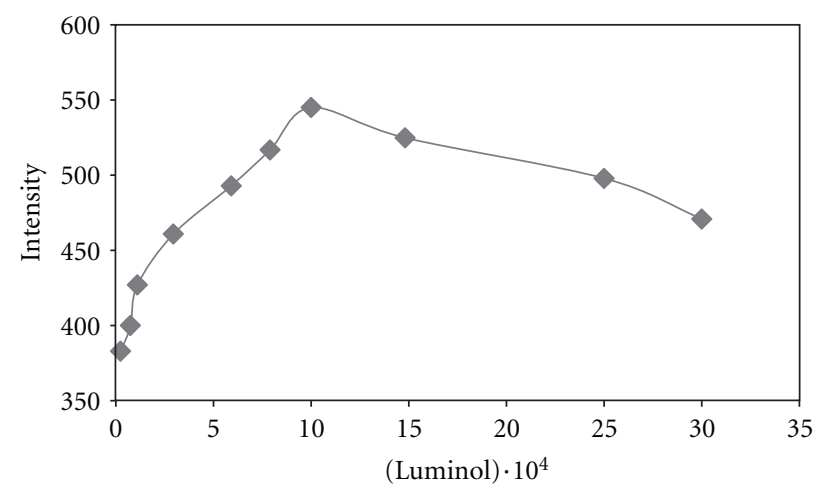

FIGURE 2: Effect of variation of the concentration of luminol on CL intensity.

of manganese porphyrin was observed at $\mathrm{pH}$ 11.8-12.5, undesirable denaturing of proteins occurred at high $\mathrm{pH}$, so the optimal $\mathrm{pH}$ in the presence of protein was evaluated at 10. The variation of CL intensity as a function of $\mathrm{pH}$ in the absence and presence of albumins is shown in Figure 5.

3.2. Study of CL Parameters Affected by Proteins. To shed light on the kinetic parameters of the chemiluminescence of luminal- $\mathrm{H}_{2} \mathrm{O}_{2}-\mathrm{MnTSPP}$ system in the absence and presence of serum albumins from the corresponding CL intensity versus time profiles and consecutive irreversible first-order reactions, this can be described by a simplified model which was employed $[33,34]$ as

$$
R \stackrel{K_{r}}{\rightarrow} X \stackrel{K_{f}}{\rightarrow} P,
$$

where $R, X$, and $P$ represent pools of reactants, intermediates, and products, respectively. Both reactions are irreversible first-order reactions. The chemiluminescence signal is proportional to the intermediate concentration. The integrated 


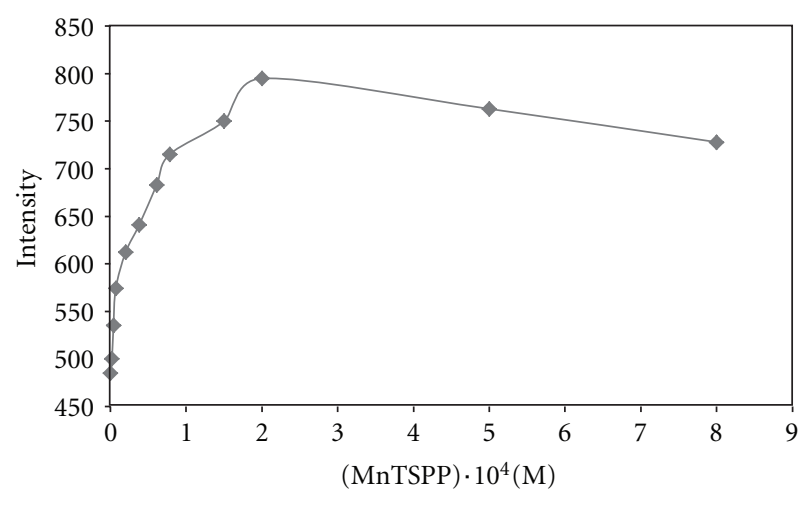

FIgURe 3: Effect of MnTSPP concentration on CL intensity.

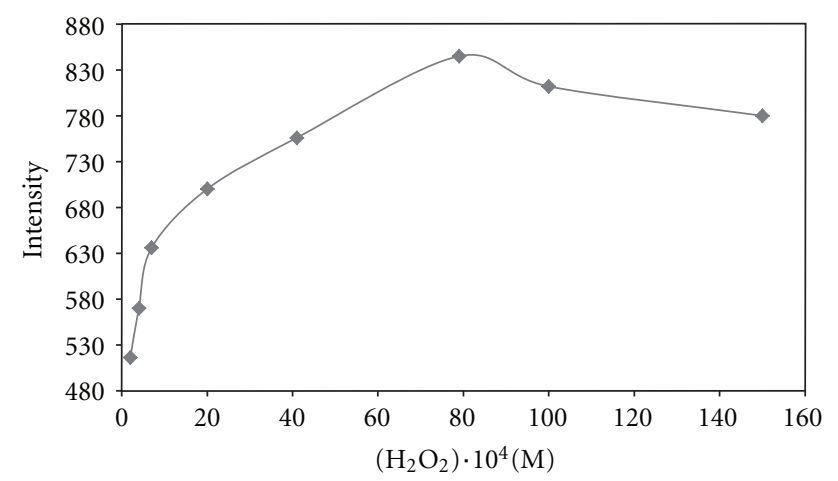

FIGURE 4: Effect of $\mathrm{H}_{2} \mathrm{O}_{2}$ concentration on CL intensity.

rate equation for $\mathrm{CL}$ intensity versus time can be obtained as follows:

$$
I_{(t)}=\frac{M k_{r}}{k_{f}-k_{r}}\left(e^{-k_{r} t}-e^{-k_{f} t}\right),
$$

where $I_{t}$ is the CL intensity at time $t$, and $M$ is the theoretical maximum level of intensity if the reactions were entirely converted to a CL-generating material. $k_{r}$ and $k_{f}$ are the pseudo-first-order rate constants for the rise and fall of the burst of CL, respectively. In addition, this pooledintermediate model permits the estimation of intensity at the maximum CL $(J)$, time of maximum intensity $\left(T_{\max }\right)$, and the total light yield $(Y)$, as follows:

$$
\begin{gathered}
T_{\max }=\frac{\operatorname{Ln}\left(k_{f} / k_{r}\right)}{k_{f}-k_{r}}, \\
J=M\left(\frac{k_{f}}{k_{r}}\right)^{\left[k_{f} /\left(k_{f}-k_{r}\right)\right]}, \\
Y=\int_{0}^{\infty} I_{(t)} d t=\frac{M}{k_{f}} .
\end{gathered}
$$

The $k_{r}, k_{f}$, and other kinetic values were evaluated by computer fitting of the CL intensity-time profiles from (2), using a nonlinear least-squares curve fitting program KINFIT [35]. Then the other parameters $J, T_{\max }$, and $Y$ were

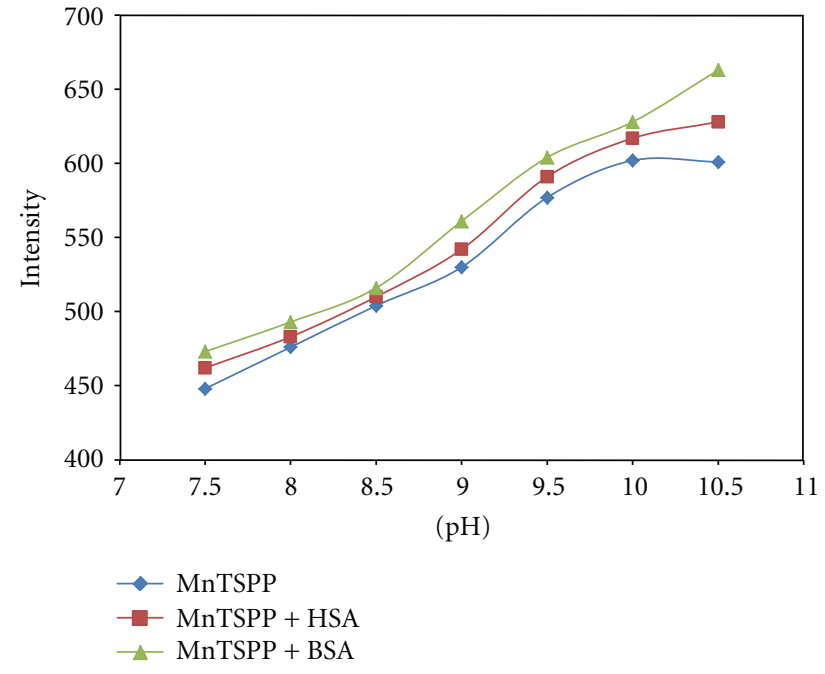

FIGURE 5: Effect of $\mathrm{pH}$ on CL intensity in the absence and presence of albumins.

evaluated from (3). All kinetic parameters were evaluated and presented in Table 1. Two typical response curves (i.e., light intensity versus time) for the luminol- $\mathrm{H}_{2} \mathrm{O}_{2}-\mathrm{MnTSPP}$ system in the absence and presence of varying concentration of HSA and BSA are shown in Figures 6 and 7, respectively. As can be seen in the absence of protein, the peak increases rapidly after mixing and reaches at maximum within $2.9 \mathrm{~s}$, and the decay of light intensity from the maximum occurs during the longer periods of time (up to $38 \mathrm{~s}$ ) via an exponential process (curve 1 in Figures 6 and 7). In the case of HSA, by first injecting $\left(1.5 \times 10^{-6} \mathrm{M}\right)$, time to reach maximum intensity increased to $3.6 \mathrm{~s}$. By increasing the concentration, $T_{\max }$ continuously increased up to $6.18 \mathrm{~s}$ at $1.5 \times 10^{-5} \mathrm{M}$ (presented by curve 2-7, Figure 6). Furthermore, as seen in Table 1, by first addition of HSA, rise and fall rate constant decreased 1.17 and 1.07 times less than during the absence of HSA. Moreover, at higher concentration of HSA $\left(1.5 \times 10^{-5} \mathrm{M}\right)$, rise and fall rate constant decreased 2.4 and 1.34 times less than the rise and fall in the absence of HSA. Other parameters as $M, J$, and $Y$ decreased sharply in direct proportion of increasing HSA concentration too.

Figure 7 shows the effect of variation of BSA concentration on intensity versus time plots. As the results shown in Table 1 , when $1.5 \times 10^{-6} \mathrm{M}$ of BSA is added to the cell, the decrease of rate constants was observed in comparison with the absence of BSA (1.26- and 1.04-fold for rise and fall rate constant, resp.), while $T_{\max }$ reaches up to $3.8 \mathrm{~s}$. Maximum of $T_{\max }$ was observed at $1.5 \times$ $10^{-5} \mathrm{M}$, while rate constants show greatest reduction (3.57 and 1.4 times for $k_{r}$ and $k_{f}$, resp.). Figures 8 and 9 show typical computer fitting of the CL intensity-time plots in the presence of HSA and BSA, respectively. Fortunately, there was an adequate agreement between the calculated $(J)$ and experimental $\left(J_{\exp }\right)$ values of the intensity at maximum CL. 
TABLE 1: CL kinetic parameters evaluated from computer fitting of the CL intensity-time for luminol-MnTSPP- $\mathrm{H}_{2} \mathrm{O}_{2}$ in the presence of serum albumins.

\begin{tabular}{cccccccccc}
\hline Parameters & $\begin{array}{c}\text { Concentration } \\
(\mathrm{M})\end{array}$ & $k_{r}\left(\mathrm{~min}^{-1}\right)$ & $k_{f}\left(\mathrm{~min}^{-1}\right)$ & $M$ & $J$ & $J_{\exp }$ & $T_{\max }(\min )$ & $T_{\exp }(\min )$ & $Y$ \\
& 0 & $80 \pm 4$ & $2.6 \pm 0.44$ & $932 \pm 2$ & 646 & 728 & 0.044 & 0.049 \\
& $1.5 \times 10^{-6}$ & $68 \pm 2$ & $2.42 \pm 0.08$ & $843 \pm 3$ & 547 & 573 & 0.051 & 0.060 & 358 \\
& $3 \times 10^{-6}$ & $64 \pm 3$ & $2.36 \pm 0.23$ & $630 \pm 2$ & 402 & 433 & 0.053 & 0.066 & 183 \\
HSA & $4.5 \times 10^{-6}$ & $58 \pm 5$ & $2.31 \pm 0.03$ & $438 \pm 6$ & 277 & 313 & 0.058 & 0.070 & 189 \\
& $6.5 \times 10^{-5}$ & $47 \pm 1$ & $2.18 \pm 0.68$ & $335 \pm 3$ & 206 & 225 & 0.068 & 0.082 & 153 \\
& $9.5 \times 10^{-6}$ & $39 \pm 4$ & $2.1 \pm 0.81$ & $276 \pm 3$ & 168 & 175 & 0.079 & 0.086 & 131 \\
& $1.5 \times 10^{-5}$ & $33 \pm 2$ & $1.94 \pm 0.2$ & $204 \pm 2$ & 177 & 133 & 0.091 & 0.103 & 105 \\
\hline \multirow{3}{*}{ BSA } & $1.5 \times 10^{-6}$ & $63 \pm 7$ & $2.49 \pm 1$ & $776 \pm 4$ & 523 & 555 & 0.053 & 0.064 & 311 \\
& $3 \times 10^{-6}$ & $53 \pm 5$ & $2.42 \pm 0.35$ & $551 \pm 2$ & 369 & 375 & 0.061 & 0.073 & 227 \\
& $4.5 \times 10^{-6}$ & $41 \pm 5$ & $2.32 \pm 0.71$ & $366 \pm 2$ & 244 & 271 & 0.074 & 0.08 & 157 \\
& $6.5 \times 10^{-5}$ & $36 \pm 4$ & $2 \pm 0.11$ & $297 \pm 1$ & 174 & 199 & 0.085 & 0.097 & 148 \\
& $9.5 \times 10^{-6}$ & $28.6 \pm 6$ & $1.93 \pm 1.2$ & $208 \pm 2$ & 122 & 157 & 0.101 & 0.110 & 107 \\
& $1.5 \times 10^{-5}$ & $22.4 \pm 6$ & $1.85 \pm 0.25$ & $157 \pm 3$ & 93 & 115 & 0.121 & 0.132 \\
\hline
\end{tabular}

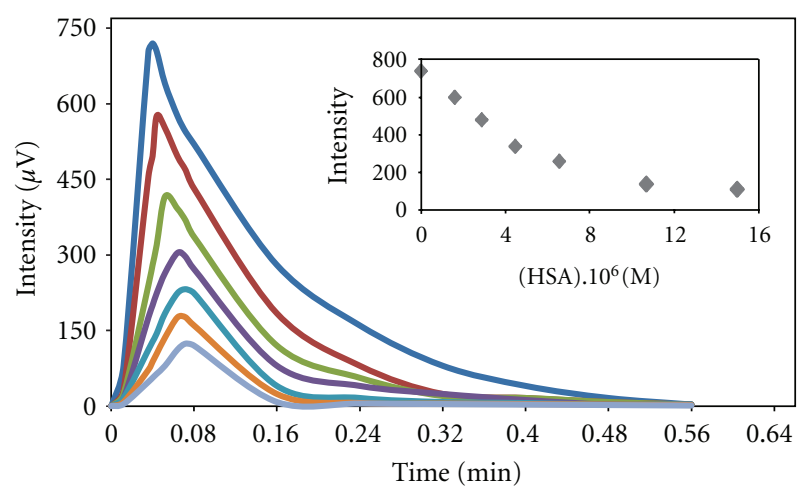

FIGURE 6: CL intensity as a function of time for reaction of luminol $\left(1 \times 10^{-3} \mathrm{M}\right), \operatorname{MnTSPP}\left(2 \times 10^{-4} \mathrm{M}\right)$ and $\mathrm{H}_{2} \mathrm{O}_{2}\left(8 \times 10^{-3} \mathrm{M}\right)$ in the presence of varying concentration of HSA. (Inset) CL intensity as a function of HSA concentration.

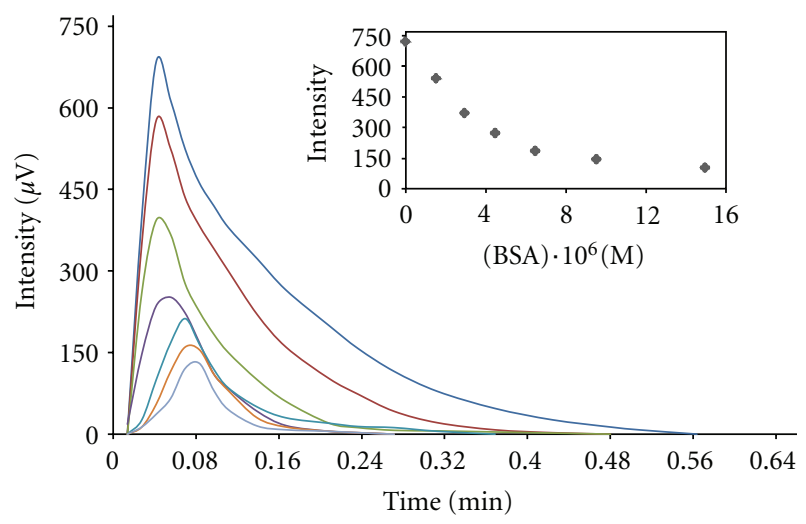

FIGURE 7: CL intensity as a function of time for reaction of luminol $\left(1 \times 10^{-3} \mathrm{M}\right), \operatorname{MnTSPP}\left(2 \times 10^{-4} \mathrm{M}\right)$ and $\mathrm{H}_{2} \mathrm{O}_{2}\left(8 \times 10^{-3} \mathrm{M}\right)$ in the presence of varying concentration of HSA. (Inset) CL intensity as a function of BSA concentration.

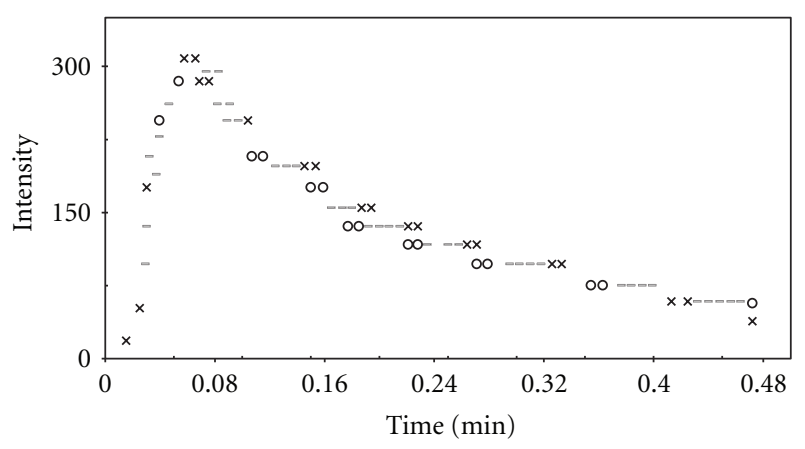

Figure 8: Computer fit of the CL intensity-time plot for luminolMnTSPP- $\mathrm{H}_{2} \mathrm{O}_{2}$ in the presence of $4.5 \times 10^{-6} \mathrm{M}$ HSA: $(\times)$ experimental point, (o) calculated point, and (=) experimental and calculated points are the same within the resolution of the plot.

3.3. The Possible Mechanism. The mechanism of the effect of serum albumins on CL reaction can be attributed to interaction of metalloporphyrins with proteins which have been reported earlier [36-42]. Metalloporphyrin can react by pyridine and amino acids with two axial coordinations. Manganese tetrasulfonatophenyl porphyrin has several aromatic rings and four sulfonic acid groups. Because of these groups, it has high affinity to the residues of aminoacids like histidine, arginine, lysine, and the amino terminal in a protein molecule. Within CL process, metalloporphyrin reacts with hydrogen peroxide and causes to catalyze the oxidation of luminol. Interaction of metalloporphyrin and proteins can inhibit peroxidase activity of metalloporphyrin to produce 3 -aminophtale and hence emitting light (Scheme 1). Table 1 shows that the rate constants and $J$ dramatically decreased as the protein concentration increased.

3.4. Study of Quenching CL by Serum Albumins. As it is obvious in Table 1, a considerable decrease in intensity of chemiluminescence system occurred as the concentrations 


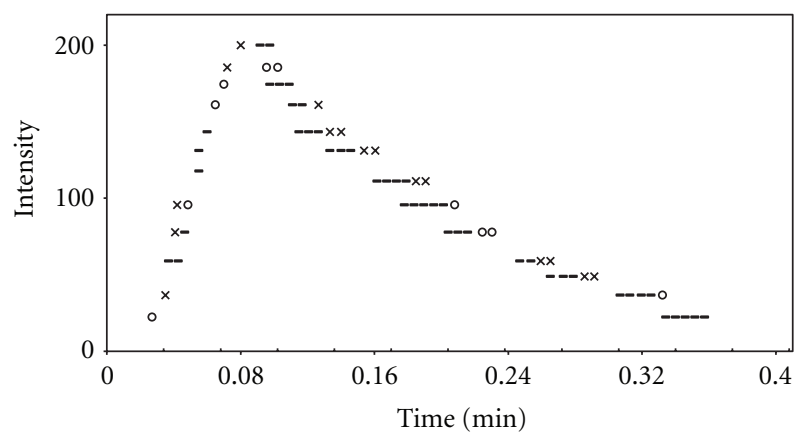

FIGURE 9: Computer fit of the CL intensity-time plot for luminolMnTSPP- $\mathrm{H}_{2} \mathrm{O}_{2}$ in the presence of $6.5 \times 10^{-5} \mathrm{M}$ BSA: $(\times)$ experimental point, (o) calculated point, and (=) experimental and calculated points are the same within the resolution of the plot.

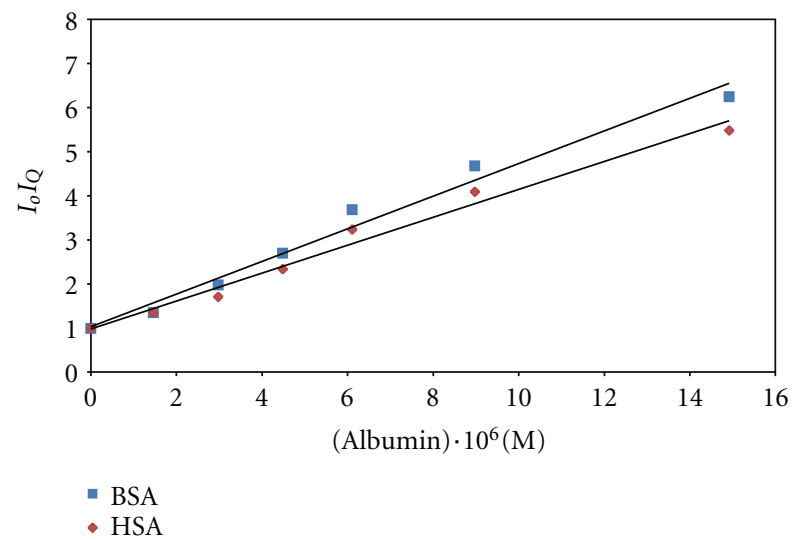

FIGURE 10: Stern-Volmer plots of $I_{o} / I_{Q}$ versus concentration of albumins.

of HSA and BSA are increased. So we decided to study the term of quenching chemiluminescences which have been described by Fletcher and Heller [43]. In the presence of quencher, chemiluminescence intensity reduced from $I_{o}$ to $I_{Q}$. The ratio of $\mathrm{Cl}$ intensity was reduced directly with quencher concentration $(Q)$ increasing, as stated by SternVolmer plots equation [44]

$$
\frac{I_{o}}{I_{Q}}=1+k_{Q}[Q],
$$

where $k_{Q}$ is the Stern-Volmer quenching constant.

Based on (4), a plot of $I_{0} / I_{Q}$ versus [Q] will result in a linear graph with an intercept of 1 and a slope of $k_{Q}$. For a measurement system based on quenching, $k_{Q}$ should be as large as possible. Plots of $I_{o} / I_{Q}$ versus concentration of HSA and BSA as quenchers were evaluated and presented in Figure 10. The resulting regression equations in the concentration range from $1.5 \times 10^{-6}$ to $1.5 \times 10^{-4} \mathrm{M}$ are as follows:

$$
\begin{array}{ll}
\frac{I_{o}}{I_{Q}}=0.953+0.317 \times 10^{6}[\mathrm{HSA}] & r^{2}=0.9792, \\
\frac{I_{o}}{I_{Q}}=0.991+0.370 \times 10^{6}[\mathrm{BSA}] & r^{2}=0.9821 .
\end{array}
$$

Decrease in $k_{r}, M, J$, and $Y$ and also increasing time to reach maximum intensity vividly verified strong inhibiting of chemiluminescence of luminol-metalloporphyrin system by albumins. It should be noted that the protein detection by the quenched chemiluminescence of luminal $-\mathrm{H}_{2} \mathrm{O}_{2}-\mathrm{Mn}$ TSPP system is based on a reduction in the CL signal due to interaction of porphyrin with proteins. As it is expected, the noise of this signal should be reduced as much as possible to achieve a favorable signal-to-noise ratio for the quenched chemiluminescence. This can be obtained easily at a high $I_{o}$ value, since a greater dynamic range is then obtainable. It can be concluded that metalloporphyrin chemiluminescence of luminol is appropriate for the quenched chemiluminescence mode in the case of proteins.

\section{Conclusion}

In this work, the effects of human and bovine serum albumin on kinetic parameters of chemiluminescence of luminol catalyzed by manganese tetrasulfonatophenyl porphyrin were studied. The investigated parameters involved pseudo-firstorder rise and fall rate constant for the chemiluminescence burst, maximum level intensity, time to reach maximum intensity, total light yield, and values of the intensity at maximum CL. It has been observed that as the albumins are interacting with metalloporphyrin, the intensity of chemiluminescence was decreased. Moreover, the Stern-Volmer plots for quenched chemiluminescence system in the presence of albumins were also evaluated.

\section{References}

[1] D. C. Carter, X. M. He, S. H. Munson et al., "Three-dimensional structure of human serum albumin," Science, vol. 244, no. 4909, pp. 1195-1198, 1989.

[2] D. C. Carter and J. X. Ho, "Structure of serum albumin," Advances in Protein Chemistry, vol. 45, pp. 153-203, 1994.

[3] T. Kosa, T. Maruyama, and M. Otagiri, "Species differences of serum albumins: I. Drug binding sites," Pharmaceutical Research, vol. 14, no. 11, pp. 1607-1612, 1997.

[4] U. Kragh-Hansen, "Molecular aspects of ligand binding to serum albumin," Pharmacological Reviews, vol. 33, no. 1, pp. 17-53, 1981.

[5] T. Peters, "Serum Albumin," Advances in Protein Chemistry, vol. 37, no. C, pp. 161-245, 1985.

[6] P. Daneshgar, A. A. Moosavi-Movahedi, P. Norouzi, M. R. Ganjali, A. Madadkar-Sobhani, and A. A. Saboury, "Molecular interaction of human serum albumin with paracetamol: spectroscopic and molecular modeling studies," International Journal of Biological Macromolecules, vol. 45, no. 2, pp. 129$134,2009$.

[7] M. R. Ganjali, F. Faridbod, A. A. Saboury et al., "A new approach for protein binding isotherm analysis by means of an electrochemical microsensor," International Journal of Electrochemical Science, vol. 5, no. 5, pp. 630-638, 2010.

[8] M. R. Ganjali, F. Faridbod, A. Divsalar et al., "Nano-composite carbon pate electrode used for biophysical study of $\mathrm{Ho}^{3+}$ ion interaction with human serum albumin," International Journal of Electrochemical Science, vol. 5, no. 6, pp. 852-866, 2010.

[9] N. Barbero, E. Barni, C. Barolo et al., "A study of the interaction between fluorescein sodium salt and bovine serum 
albumin by steady-state fluorescence," Dyes and Pigments, vol. 80, no. 3, pp. 307-313, 2009.

[10] T. O. Hushcha, A. I. Luik, and Y. N. Naboka, "Conformation changes of albumin in its interaction with physiologically active compounds as studied by quasi-elastic light scattering spectroscopy and ultrasonic method," Talanta, vol. 53, no. 1, pp. 29-34, 2000.

[11] Y. Wang, M. Schubert, A. Ingendoh, and J. Franzen, "Analysis of non-covalent protein complexes up to $290 \mathrm{kDa}$ using electrospray ionization and ion trap mass spectrometry," Rapid Communications in Mass Spectrometry, vol. 14, no. 1, pp. 12-17, 2000.

[12] Z. Wang, Z. Zhang, Z. Fu, Y. Xiong, and X. Zhang, "A flowinjection ultrafiltration sampling chemiluminescence system for on-line determination of drug-protein interaction," Analytical and Bioanalytical Chemistry, vol. 377, no. 4, pp. 660665, 2003.

[13] A. M Garcia-Campana, Chemiluminescence in Analytical Chemistry, W. R. G. Baeyens, Ed., Marcel Dekker, New York, NY, USA, 2001.

[14] X. Y. Yang, Y. S. Guo, S. Bi, and S. S. Zhang, "Ultrasensitive enhanced chemiluminescence enzyme immunoassay for the determination of $\alpha$-fetoprotein amplified by double-codified gold nanoparticles labels," Biosensors and Bioelectronics, vol. 24, no. 8, pp. 2707-2711, 2009.

[15] T. Tanaka and T. Matsunaga, "Fully automated chemiluminescence immunoassay of insulin using antibody-protein Abacterial magnetic particle complexes," Analytical Chemistry, vol. 72, no. 15, pp. 3518-3522, 2000.

[16] J. Lin and H. Ju, "Electrochemical and chemiluminescent immunosensors for tumor markers," Biosensors and Bioelectronics, vol. 20, no. 8, pp. 1461-1470, 2005.

[17] P. M. Gillevet, "Chemiluminescent multiplex DNA sequencing," Nature, vol. 348, no. 6302, pp. 657-658, 1990.

[18] P. G. Gillespie and A. J. Hudspeth, "Chemiluminescence detection of proteins from single cells," Proceedings of the National Academy of Sciences of the United States of America, vol. 88, no. 6, pp. 2563-2567, 1991.

[19] K. Aslan and C. D. Geddes, "Metal-enhanced chemiluminescence: advanced chemiluminescence concepts for the 21st century," Chemical Society Reviews, vol. 38, no. 9, pp. 25562564, 2009.

[20] C. A. Marquette and L. J. Blum, "Applications of the luminol chemiluminescent reaction in analytical chemistry," Analytical and Bioanalytical Chemistry, vol. 385, no. 3, pp. 546-554, 2006.

[21] M. Motsenbocker, Y. Ichimori, and K. Kondo, "Metal porphyrin chemiluminescence reaction and application to immunoassay," Analytical Chemistry, vol. 65, no. 4, pp. 397402, 1993.

[22] K. Komagoe and T. Katsu, "Porphyrin-induced photogeneration of hydrogen peroxide determined using the luminol chemiluminescence method in aqueous solution: a structureactivity relationship study related to the aggregation of porphyrin," Analytical Sciences, vol. 22, no. 2, pp. 255-258, 2006.

[23] Q. Zhu, "A novel chemiluminescent flow injection analysis of trace amounts of rutin by its inhibition of the luminolhydrogen peroxide reaction catalyzed by tetrasulfonated colbalt phthalocyanine," Luminescence, vol. 24, no. 4, pp. 250254, 2009.

[24] W. Xu, Y. Wei, D. Xing, and Q. Chen, "A novel chemiluminescence technique for quantitative measurement of low concentration human serum albumin," Analytical Sciences, vol. 24, no. 1, pp. 115-119, 2008.
[25] Z. Wang, Z. Song, and D. Chen, "Study on the binding behavior of bovine serum albumin with cephalosporin analogues by chemiluminescence method," Talanta, vol. 83, no. 2, pp. 312$319,2010$.

[26] J. Zhou, D. Xing, and Q. Chen, "Enhancement of fluoresceinyl Cypridina luciferin analog chemiluminescence by human serum albumin for singlet oxygen detection," Photochemistry and Photobiology, vol. 82, no. 4, pp. 1058-1064, 2006.

[27] S. Aoyagi, T. Iwata, T. Miyasaka, and K. Sakai, "Determination of human serum albumin by chemiluminescence immunoassay with luminol using a platinum-immobilized flow-cell," Analytica Chimica Acta, vol. 436, no. 1, pp. 103-108, 2001.

[28] Y. Li, D. Zhao, C. Zhu, L. Wang, and J. Xu, "Determination of proteins at nanogram levels by their quenching effect on the chemiluminscence reaction between luminol and hydrogen peroxide with manganese-tetrasulfonatophthalocyanine as a new catalyst," Analytical and Bioanalytical Chemistry, vol. 374, no. 3, pp. 395-398, 2002.

[29] Z. Li, K. Li, and S. Tong, "Study of the catalytic effect of Copper(II)-protein complexes on luminol-H2O2 chemiluminescence reaction and its analytical application," Analytical Letters, vol. 32, no. 5, pp. 901-913, 1999.

[30] W. Cao, Y. Fu, P. Gong, Y. Ma, S. Qiao, and J. Yang, "Nbromosuccinimide-fluorescein system for the determination of protein by flow injection chemiluminescence," Microchimica Acta, vol. 168, no. 1-2, pp. 17-21, 2010.

[31] X. Tan, Z. Song, D. Chen, and Z. Wang, "Study on the chemiluminescence behavior of bovine serum albumin with luminol and its analytical application," Spectrochimica Acta. Part A, vol. 79, no. 1, pp. 232-235, 2011.

[32] C. B. Huang, K. Zhang, X. L. Liu, and S. F. Wang, "A flowinjection chemiluminescence method for the determination of human serum albumin, using the reaction of fluoresceinhuman serum albumin-sodium hypochlorite by the enhancement effect of the cationic surfactant cetyltrimethylammonium bromide," Luminescence, vol. 22, no. 5, pp. 393-400, 2007.

[33] M. Orlović, R. L. Schowen, R. S. Givens, F. Alvarez, B. Matuszewski, and N. Parekh, "A simplified model for the dynamics of chemiluminescence in the oxalate-hydrogen peroxide system: toward a reaction mechanism," Journal of Organic Chemistry, vol. 54, no. 15, pp. 3606-3610, 1989.

[34] A. G. Hadd, A. Seeber, and J. W. Birks, "Kinetics of two pathways in peroxyoxalate chemiluminescence," Journal of Organic Chemistry, vol. 65, no. 9, pp. 2675-2683, 2000.

[35] J. L. Dye and V. A. Nicely, "A general purpose curvefitting program for class and research use," Journal of Chemical Education, vol. 48, no. 7, pp. 443-448, 1971.

[36] M. Kořínek, R. Dědic, A. Molnár, and J. Hála, "The influence of human serum albumin on the photogeneration of singlet oxygen by meso-tetra(4-sulfonatophenyl) porphyrin. An infrared phosphorescence study," Journal of Fluorescence, vol. 16, no. 3, pp. 355-359, 2006.

[37] I. E. Borissevitch, T. T. Tominaga, H. Imasato, and M. Tabak, "Resonance light scattering study of aggregation of two water soluble porphyrins due to their interaction with bovine serum albumin," Analytica Chimica Acta, vol. 343, no. 3, pp. 281-286, 1997.

[38] I. E. Borissevitch, T. T. Tominaga, H. Imasato, and M. Tabak, "Fluorescence and optical absorption study of interaction of two water soluble porphyrins with bovine serum albumin. The role of albumin and porphyrin aggregation," Journal of Luminescence, vol. 69, no. 2, pp. 65-76, 1996. 
[39] T. T. Tominaga, V. E. Yushmanov, I. E. Borissevitch, H. Imasato, and M. Tabak, "Aggregation phenomena in the complexes of iron tetraphenylporphine sulfonate with bovine serum albumin," Journal of Inorganic Biochemistry, vol. 65, no. 4, pp. 235-244, 1997.

[40] V. E. Yushmanov, T. T. Tominaga, I. E. Borissevitch, H. Imasato, and M. Tabak, "Binding of manganese and iron tetraphenylporphine sulfonates to albumin is relevant to their contrast properties," Magnetic Resonance Imaging, vol. 14, no. 3, pp. 255-261, 1996.

[41] S. M. Andrade and S. M. B. Costa, "Spectroscopic studies on the interaction of a water soluble porphyrin and two drug carrier proteins," Biophysical Journal, vol. 82, no. 3, pp. 16071619, 2002.

[42] Q. Li and S. Seeger, "Deep UV sensing of the interaction of porphyrin with bovine serum albumin protein," Sensors and Actuators B, vol. 139, no. 1, pp. 118-124, 2009.

[43] A. N. Fletcher and C. A. Heller, "Chemiluminescence quenching terms," Photochemistry and Photobiology, vol. 4, no. 6, pp. 1051-1058, 1965.

[44] O. Stern and M. Volmer, "The extinction period of fluorescence," Phys Z, vol. 20, pp. 183-188, 1919. 


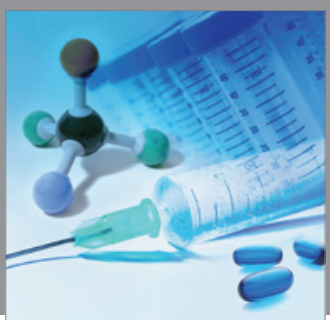

International Journal of

Medicinal Chemistry

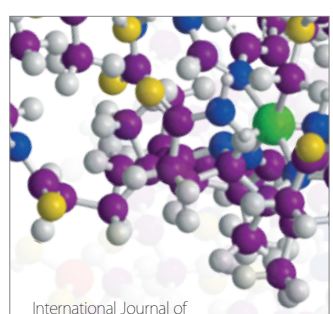

Carbohydrate Chemistry

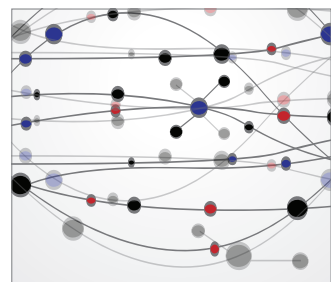

The Scientific World Journal
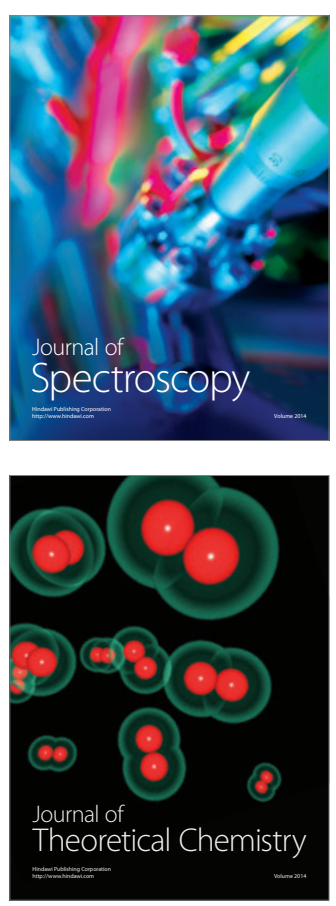
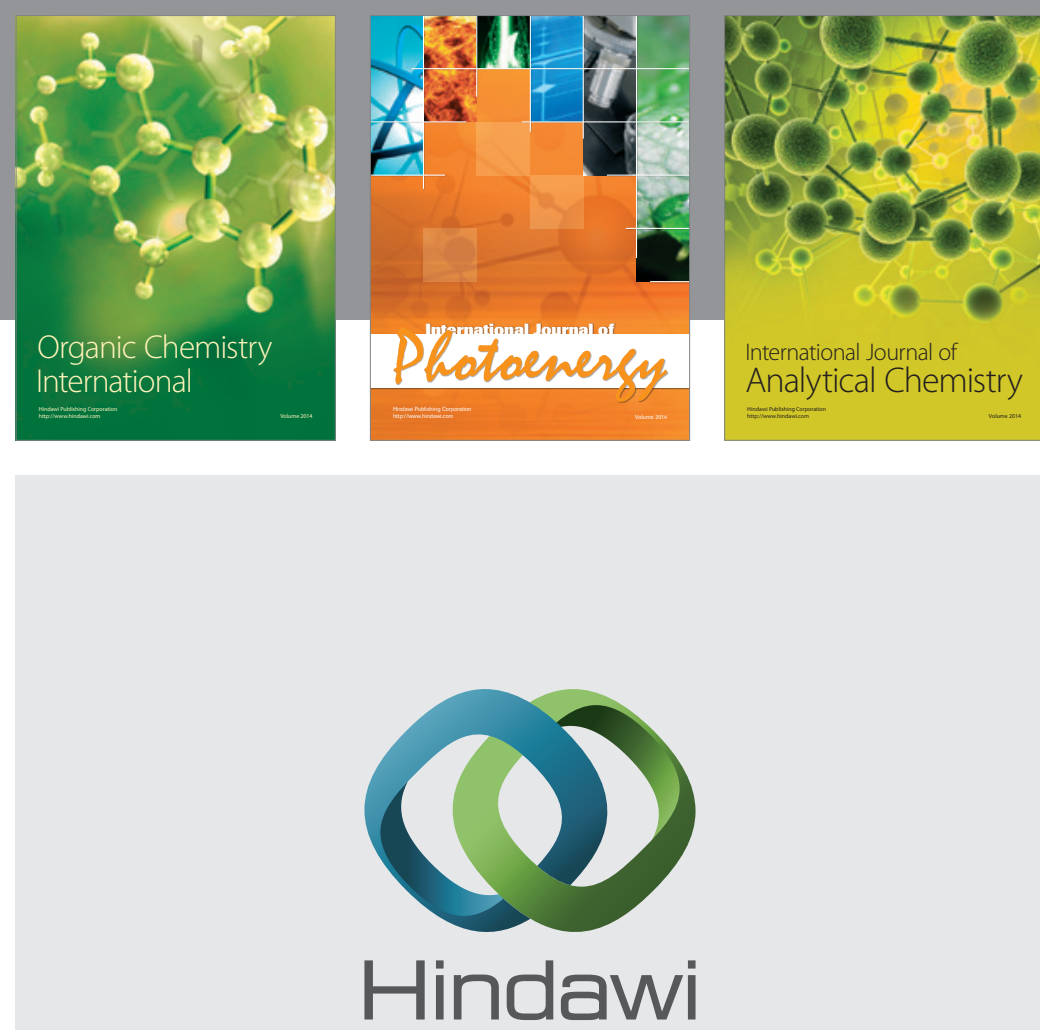

Submit your manuscripts at

http://www.hindawi.com
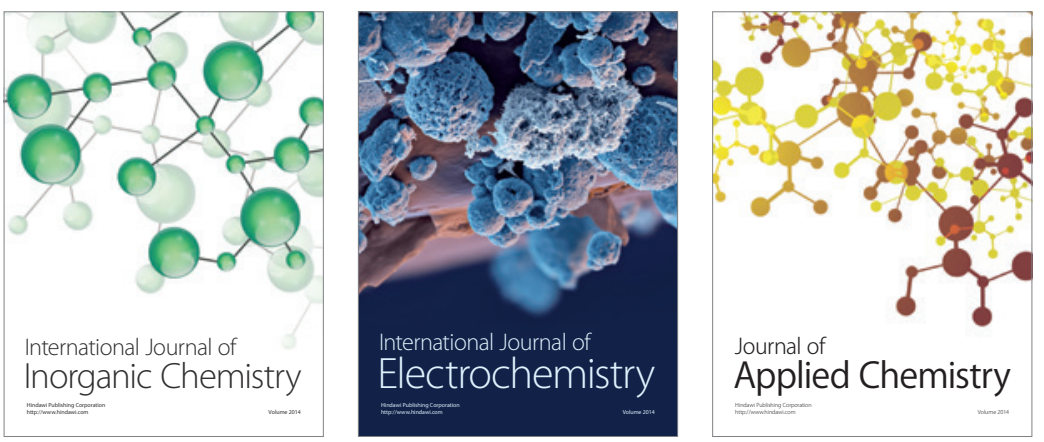

Journal of

Applied Chemistry
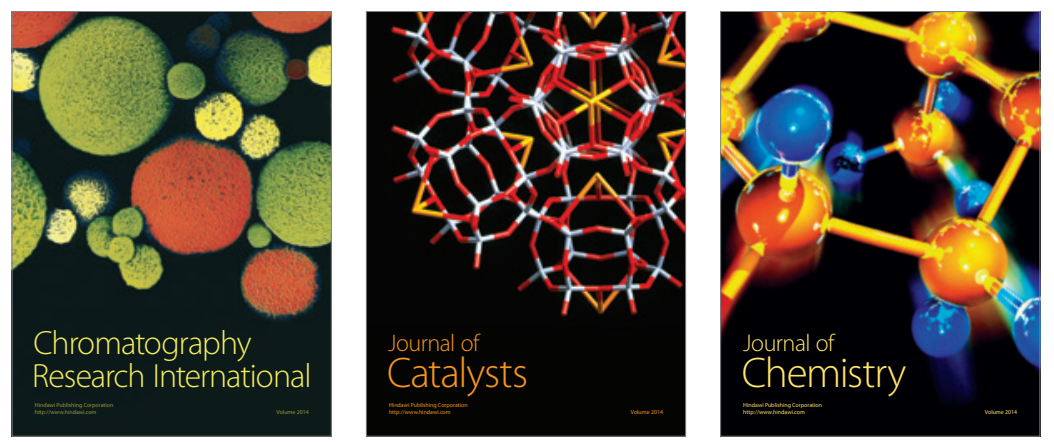
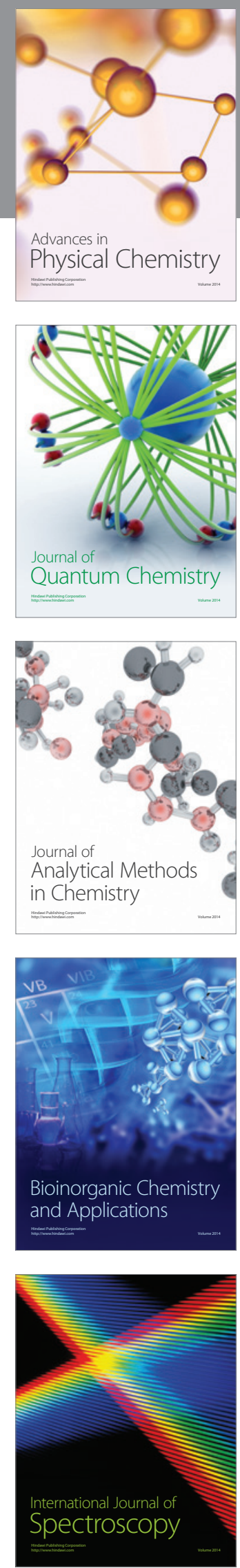